\title{
Spider Monkey Home Ranges: A Comparison of Radio Telemetry and Direct Observation
}

\author{
LINDA M. FEDIGAN ${ }^{1}$, LAURENCE FEDIGAN ${ }^{2}$, COLIN CHAPMAN ${ }^{3}$, AND \\ KENNETH E. GLANDER ${ }^{4}$ \\ ${ }^{1}$ Department of Anthropology, University of Alberta, Edmonton, Alberta, ${ }^{2}$ Faculte St. Jean, \\ University of Alberta, Edmonton, Alberta, ${ }^{3}$ Department of Biology, McGill University, \\ Montreal, Quebec, Canada, and ${ }^{4}$ Department of Anthropology, Duke University, Durham, \\ North Caroline
}

The ranging patterns of two male and five female spider monkeys (Ateles geoffroyi) were studied with the use of radio telemetry in Santa Rosa National Park, Costa Rica. The average size of a spider monkey home range was 62.4 hectares; however, range size varied with sex, and, for females, with the presence of a dependent infant. The probability of encountering a radio-collared spider monkey in a three-hour search using radio telemetry $(0.91)$ was much greater than using a visual search $(0.20)$, and telemetric data resulted in a larger estimate of mean home range size than did observational data, when all subjects were compared. However, the difference appeared to be owing to the presence of male ranges in the telemetric, but not the observational, data. When the size of home ranges derived from radio-tracking data for adult females was compared to size of ranges for adult females derived from observations, the results were not significantly different. Adult males had larger home ranges than adult females, thus lending support to the hypothesis that males have adapted to the dispersion of females by occupying a large home range that overlaps the ranges of several adult females. The smallest home ranges were occupied by low-weight females with dependent infants, perhaps reflecting social and energetic constraints.

\section{Key words: social organization, Ateles, home range}

\section{INTRODUCTION}

Radio tracking is a technique used extensively in research on mammalian behaviour and ecology, and is particularly helpful when studying elusive animals or working under difficult field conditions [Amlaner \& MacDonald, 1979]. There are, however, few published reports of radio tracking primates [but see Jones \& Bush, 1988; Bearder \& Martin, 1979; Charles-Dominique, 1977; Charles-Dominique \& Bearder, 1979; Gautier, 1983; Harcourt \& Nash, 1986; Nash \& Harcourt, 1986], perhaps because most diurnal primate species occur in consistent and recognizable

Received September 3, 1987, revision accepted May 18, 1988.

Address reprint requests to Dr. Linda M. Fedigan, Department of Anthropology, University of Alberta, Edmonton, Alberta, Canada. 


\section{0 / Fedigan et al.}

groups, which are found quite easily within relatively small, permanent home ranges. The ability to locate an animal and to track its movement and activity patterns through radio signals is most useful when the species occurs in inhospitable habitats or is solitary, nocturnal, difficult to follow, or shy of human observers. The spider monkey (Ateles geoffroyi) fulfills several of these criteria. It occurs in small, unstable subgroups of one to thirty individuals, which move rapidly through the upper canopy over relatively large areas of tropical forest. The dispersed and fluctuating nature of spider monkey social groups and the difficulties of following an adept arboreal primate means that some essential aspects of the Ateles social system remain poorly understood despite several good field studies of their behaviour [e.g., Klein, 1972; Klein \& Klein, 1975; Cant, 1976; Coelho et al., 1976; Fedigan and Baxter, 1984; McFarland, 1986, 1987].

As part of a long-term study of spider monkeys in Santa Rosa National Park in Costa Rica, we captured, marked, and released 13 individuals over a 2-year period and placed radio collars on seven of them. This was done with two objectives in mind: 1) to assess the feasibility of using radio telemetry to track an arboreal, fast-moving primate, and 2) to better understand specific aspects of their social organization by determining the home ranges of identifiable individuals.

It had been hypothesized previously [Fedigan \& Baxter, 1984] from observations of spider monkeys in Guatemala, and from a theoretical model of Ateles social organization, that male spider monkeys would have larger home ranges than females. (McFarland's observations in Peru in 1986 led to the same conclusion.) Briefly, the model suggests that a diet of highly nutritious and widely dispersed food items, such as fruit, leads to the dispersion of individual females with their dependent young. Since one male cannot guard, provide for, protect, or attempt to control the movement of a group of widely dispersed females, the dispersion of food resources is said to impede the evolution of polgyny. One "solution to the problem" of dispersed females [for other solutions see Fedigan and Baxter, 1984] would be for a group of related males to cooperatively overlap the ranges of several femaleoffspring units and to defend their large, communal range against encroachments by other "communities" of males. Wrangham [1979a,b, 1980] argued that this is the pattern found in chimpanzees, and he, as well as Fedigan and Baxter [1984], hypothesized that a similar pattern would prove to be the case in Ateles. The documentation of differences between the sexes in home range size would lend support to this hypothesis. Further, since chimpanzee females with infants are reported to have restricted ranges in comparison to those without, the present study also examines variation in adult female spider monkey home ranges.

\section{METHODS}

Santa Rosa National Park is situated approximately $35 \mathrm{~km}$ northwest of Liberia in Guanacaste province, Costa Rica. It lies between the Pan American highway and the Pacific Ocean and covers approximately 10,800 ha. It consists of a number of stepped plateaus that start at an elevation of $300 \mathrm{~m}$ and gradually drop down to a coastal plain. Annual rainfall in the park ranges between $900 \mathrm{~mm}$ and $2200 \mathrm{~mm}$. The park consists of a mosaic of distinct habitat types that result from past land use practices and from naturally varying environmental conditions. Originally the park was covered by a dry, deciduous forest with patches of oak forest (Quercus oleoides) along the highest and eastern side of the park [Janzen, 1986]. However, over the past 300 years, a large portion of the upper plateau was cleared for cattle pasture and planted with the grass, Hyparrhenia rufa, and much of the remaining forest has been selectively logged. With the establishment of the park, cattle were gradually removed, and the pastures have been reverting to 
woody vegetation. The mosaic of habitat types that has resulted from this diverse land use pattern includes various serial stages of dry deciduous forest and sections of semi-evergreen forest, found primarily in the riverine areas. Within this mosaic, forested patches often have sharp boundaries and are nearly isolated. As a consequence, many patches are linked only by narrow corridors of trees along streams, ravines, and ridges.

In 1985 and 1986, spider monkeys were captured by darting with a Pneu-Dart (model 176) tranquilizer gun. For details of capture technique and success rate, see Glander et al. (in prep). The tranquilized individuals were weighed, measured, photographed, and fitted with dog collars and tags, or specially designed anklets with identifiable colored beads. Each individual received a unique combination of color and shape of markers. In addition, two adult male spider monkeys and five adult females were fitted with radio collars.

The radios, made by Austec Electronics of Edmonton, were $3.5 \mathrm{v}$, single cell, KT80 transmitters, with a lifespan of 2 to 3 months. Each radio was sealed in a small plastic container stapled at one side to the end of a leather collar into which the aerial was sewn. After capture, we sewed the other side of the plastic containers to the leather collars by cotton thread so that in time the cotton would rot and the collar with the dead radio transmitter would fall off. For practical information on radio transmitters see MacDonald and Amlaner [1979] and Morris [1979].

Once released, the radio-collared individuals were tracked through two techniques: periodic fixes and all-day follows. "Periodic fixes" were a one-time contact and localization of the animal, and were used primarily in the first few days after release, as we adjusted to the movement patterns of the animal. Thereafter, periodic fixes were taken only when the opportunity arose because the long-term following of one individual led us within range of a second radio-collared animal. All-day follows were attempts to track a monkey from dawn to dusk. Up to eight people relayed each other in teams of two, during four shifts in each day. The radio-collared monkeys were followed on a rotational schedule, one for each day, with readings being taken approximately every 30 minutes. We continued to track each monkey for the 2-3 months during which the transmitters were functional. Thus, the home range estimates for each radio-collared monkey result from the field session during which it was captured, either 1985 or 1986.

A network of approximately $25 \mathrm{~km}$ of trails was cut through the areas in which the monkeys were captured, and some previous trails and roads in the park were accessible by jeep. Although most of the radio tracking was done on foot, some initial contacts were made by having a person sit on top of a slowly moving jeep, holding up the antenna. Trails were also walked in a systematic manner until a clear radio signal was picked up, at which point following could begin. The antenna was rotated in space to achieve a directional reading, the strength of the signal increasing when the antenna was pointed in the correct direction. The strength of the signal also increased with proximity to the animal. With practice, we were able to judge our distance from the monkey fairly accurately by the strength of the signal.

Because spider monkeys are very mobile, and travel in variably sized groups that we wanted to identify, and because very little was known about their movements in Santa Rosa (especially male patterns), stationary triangulation was not used. Small portable receivers and collapsible antenna allowed us greater flexibility and closer contact. However, occasionally two receivers were used, one stationary in an elevated position, the other mobile. Topological and phenological features (e.g., fruiting patches), visible and audible branch movements, and 


\section{2 / Fedigan et al.}

contact vocalizations were used to supplement signal strength and to pinpoint position. This allowed greater monitoring of group movement, especially of fissioning and fusing, and the possibility of counting group size and composition. When there was doubt about exact location, the unencumbered member of the team would approach the subject slowly and discretely, to obtain auditory or visual information. At the end of each shift, a deliberate attempt was made to contact the subject and identify other individuals with which it was traveling.

The terrain in which we worked at Santa Rosa is relatively flat and, during the dry season, the foliage is generally sparse, the dry forest being sown with patches of evergreen or seasonally leafing and fruiting trees. Trials made after the onset of the rainy season showed the signal to be more variable and more rapidly attenuating, lowering the efficiency and reliability of the method. There was a decrease in the distance at which we could pick up the signal, falling from half a kilometre to approximately 150 metres. Because of these factors, all radio-tracking data reported in this study were collected during the dry seasons.

During the months of radio tracking, team members also were sent over the trails in the study area, without the radio receiver, to make visual searches for the radio-collared spider monkeys over a comparable period of time to a radio-tracking shift. This was done to allow comparisons of the success rate in finding monkeys using the two techniques. A $120 \times 120 \mathrm{~m}$ grid was superimposed on an aerial photograph of the study area and all locations of the monkeys were plotted within a cell of this grid. Since, known individual trees could often be identified on the aerial photograph, we felt that the error in estimating location was small, and rarely resulted in the animal being recorded in the wrong cell of the grid. Home ranges were considered to be the sum of those cells of the grid in which the animal was located, or would have had to pass through to get from one location point to the next.

As part of a separate observational study of the foraging strategies and social organization of all three species of primates in the park (Ateles geoffroyi, Alouatta palliata, Cebus capucinus), known spider monkeys were located and followed in order to record focal animal data. This larger observational study was conducted between 1984 and 1986 . Over this period, 24 months were spent in the field in three 8-month seasons, and 335 hours of focal animal data were collected on Ateles [see Chapman and Chapman, 1987, and Chapman, 1987 for a more detailed description of the protocol]. All of the radio-tracked monkeys (except the largest male) as well as an additional six marked spider monkeys were independently located by visual searches as part of the observational study. Thus the home range estimates from the observational sightings result from at least one field season and in most cases two field seasons of work [1985 and 1986]. The range use patterns from the observational study are compared to the range use data calculated from the radio telemetry study.

\section{RESULTS}

The average home range size, as calculated from the radio-telemetry data, was 62.4 ha; however there was considerable variation between individuals, ranging from 37.4 ha for an adult female with an infant to 97.9 ha for the largest adult male (Table I, Figs. 1 and 2). The average number of "sightings" from which these estimates were derived was 111 (range 46 to 170). There was no relationship between the number of "sightings" of radio-collared individuals and their home range $(r=0.026, P=0.48)$, suggesting that the number of sightings obtained was sufficient to accurately calculate the home range size of spider monkeys. Thus, 
TABLE I. Weights and Estimated Home Ranges of 13 Spider Monkeys at Santa Rosa National Park, Costa Rica

\begin{tabular}{rlccccc}
\hline $\begin{array}{c}\text { Subject } \\
\text { number }\end{array}$ & \multicolumn{1}{c}{$\begin{array}{c}\text { Age/ } \\
\text { sex/class }\end{array}$} & $\begin{array}{c}\text { Weight } \\
\text { ks. }\end{array}$ & $\begin{array}{c}\text { Number } \\
\text { of radio } \\
\text { "sightings" }\end{array}$ & $\begin{array}{c}\text { Estimated } \\
\text { home } \\
\text { range }\end{array}$ & $\begin{array}{c}\text { Number of } \\
\text { observational } \\
\text { "sightings"b }\end{array}$ & $\begin{array}{c}\text { Estimated } \\
\text { home } \\
\text { range }\end{array}$ \\
\hline 1 & Adult male & 9.00 & 59 & 97.9 & - & - \\
2 & Adult male & 7.75 & 114 & 88.0 & 29 & 51.8 \\
3 & Adult female & 6.35 & 165 & 57.0 & 38 & 57.6 \\
4 & Adult female & 6.80 & 170 & 61.1 & 34 & 36.0 \\
5 & Adult female & 6.00 & 161 & 55.2 & 13 & 34.6 \\
6 & Adult female & 7.20 & 46 & 40.3 & 54 & 37.4 \\
7 & Adult female & 7.25 & 60 & 37.4 & 62 & 44.6 \\
8 & Adult female & 7.00 & - & - & 33 & 41.8 \\
9 & Adult female & - & - & - & 30 & 31.7 \\
10 & Adult female & 7.00 & - & - & 30 & 53.3 \\
11 & Adult female & 6.00 & - & - & 14 & 24.5 \\
12 & Large juvenile female & 4.00 & - & - & 12 & 36.0 \\
13 & Large juvenile male & - & - & - & 26 & 49.0 \\
& X $=$ & $6.7(3)^{\mathrm{c}}$ & 110.7 & 62.4 & 31.3 & 41.5 \\
\hline
\end{tabular}

aData collected April-June 1985; March-June, 1986.

bData collected January 1984 to August 1986.

cMean weight for adult females only.

with additional sightings of an individual, the estimate of the home range size of radio-collared animals would not likely increase.

The observational study estimated that the average home range size of spider monkeys was 41.5 ha (range 24.5 to 57.6). The difference between this estimate and that derived from the radio-telemetry study was significant $(t=2.80, P=0.05)$. Although the observational data consistently resulted in smaller estimates of home ranges than the radio-telemetry data, the ranging patterns derived from these two techniques may be more similar than the comparison of the overall means suggests. The sample of radio-tracked animals includes two wider-ranging males and the observational sample includes two immature spider monkeys. If we simply compare the estimates for adult females, the mean home range size calculated from the radio-telemetry data $(50.2 \mathrm{ha})$ is much closer to the mean home range size derived from the observational data $(40.1 \mathrm{ha}, \mathrm{t}=1.379, \mathrm{P}=0.35)$.

The success rate of contacting radio-collared individuals was much greater with radio tracking than with simple visual searches. The probability of locating a radio-collared spider monkey during a 3-hour search using functional radio equipment was 0.91 , whereas the success rate per visual search over a comparable time period was only 20 .

The radio-telemetry data allow us to begin to test predictions derived from a model of spider monkey social organization. Fedigan and Baxter [1984] predicted that male spider monkeys would have larger home ranges than adult females. The larger of the two males captured in our study had the largest home range of any animal (97.9 ha). His home range was $60 \%$ larger than the largest home range of any adult female (61.1 ha) and was $95 \%$ larger than the average radio-tracked adult female home range. The second male had the second largest home range size ( $88 \mathrm{ha}$ ). On the basis of the radio-tracking data, male home ranges were considerably larger than females ( $\bar{X} 93$ ha vs. $\bar{X}=50.2$. No test for significance was conducted due to the small sample size of males. However, note that the male mean is nearly twice that of the females). We feel that the difference between male and 
24 / Fedigan et al.
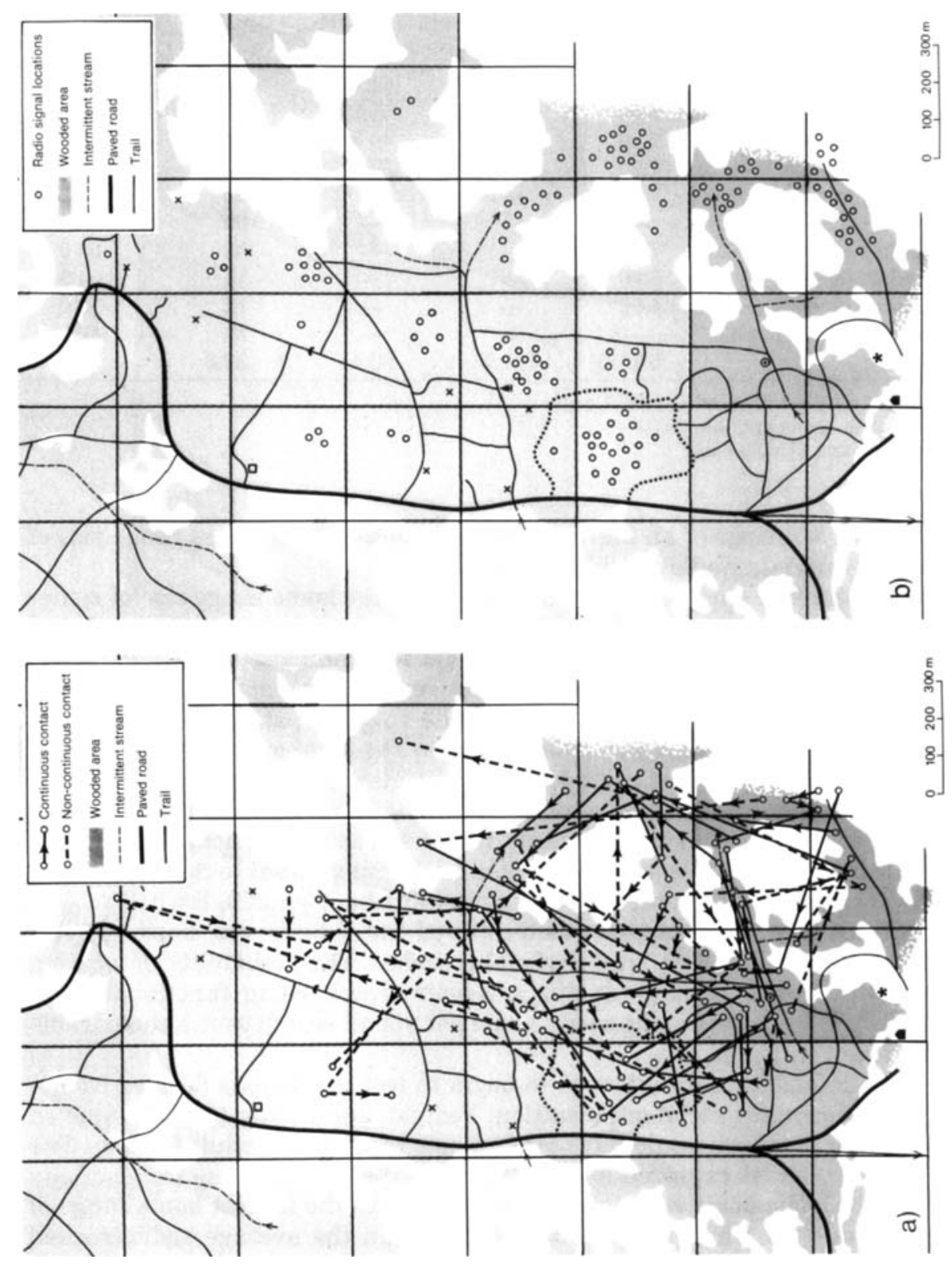
female ranges may be even stronger than is depicted here. The second of the males that we considered "adult," based on his dentition, had a smaller home range than the first radio-collared adult male, and he weighed $1.25 \mathrm{~kg}$ less than the larger male. The smaller male also rarely travelled in all-male groups, but rather ranged with another male of approximately his own body size or with females, particularly one adult female, who, based on the intensity of affiliative interactions, may have been his mother. Thus we suggest that although the small male may have been physically mature, he had not finished growing, or taken on the ranging patterns of a fully adult male as exemplified by the larger radio-tracked male.

Using observational data from 1986, when we were following four females with infants and four females without, we found that there was a trend $(t=1.65$, $\mathrm{P}=0.06$ ) for females with dependent infants to have smaller home ranges $(\overline{\mathrm{X}}=39.9)$ than those of females without infants $(\overline{\mathrm{X}}=50.2)$. However, there may be variability in whether or not the presence of a dependent infant restricts the movements of any particular mother. For instance, one female had a dependent infant in 1984 and 1985, whereas in 1986 her immature son had become independent, and only rarely travelled with her. The size of this adult female's home range in the years that the immature male travelled with her was very similar in size to her home range after the immature male was not travelling with her. Again, using observational data from 1986, we found that the variation in range size among females with infants was significantly correlated with their body weight ( $\mathrm{rsp}=1.00, \mathrm{P}<0.01$ ). However, there was no significant correlation between range size and body weight for females without infants ( $r s p=0.737$, $\mathbf{P}=0.131$ ). Thus the smallest range sizes in our sample occurred in low-weight females with infants.

The ranges of individuals overlapped extensively. There was only one 120 by $120 \mathrm{~m}$ grid cell that was not used by more than one identifiable spider monkey. Since the home ranges of the adult males were larger than the home ranges of adult females, male home ranges tended to overlap the home ranges of several females. However, the home ranges of all adult females overlapped those of neighboring females, with whom they often travelled.

\section{DISCUSSION}

The radio-telemetry study resulted in a larger estimate of mean home range size than did the observational method when all subjects are compared, in spite of the fact that the observational study was conducted over a longer period and across seasons. However, when only adult females are compared, the estimates derived from the two methods are not significantly different. This is largely the result of the fact that radio-tracking facilitates the repeated location of wide-ranging males in the outlying areas of their home range, whereas telemetry does less to augment the home range estimates of the females with their more circumscribed ranges. However, radio tracking does still facilitate the locating of adult female spider monkeys, as demonstrated by our measures of success rates in contacting collared individuals, and this study also demonstrates that the effort that must be devoted to both techniques to reach a similar level of accuracy is very different. The reason that radio telemetry can result in a reasonably accurate estimate of home range size in such a short time period (2-3 months as opposed to one or more 8-month field sessions) is that the radios greatly increase a researcher's efficiency in

Fig. 1. Telemetric data and range maps for adult female number 3. a: Travel patterns. b: Locations from which subject number 3 's radio signal emanated on one or more occasions. 
26 / Fedigan et al.
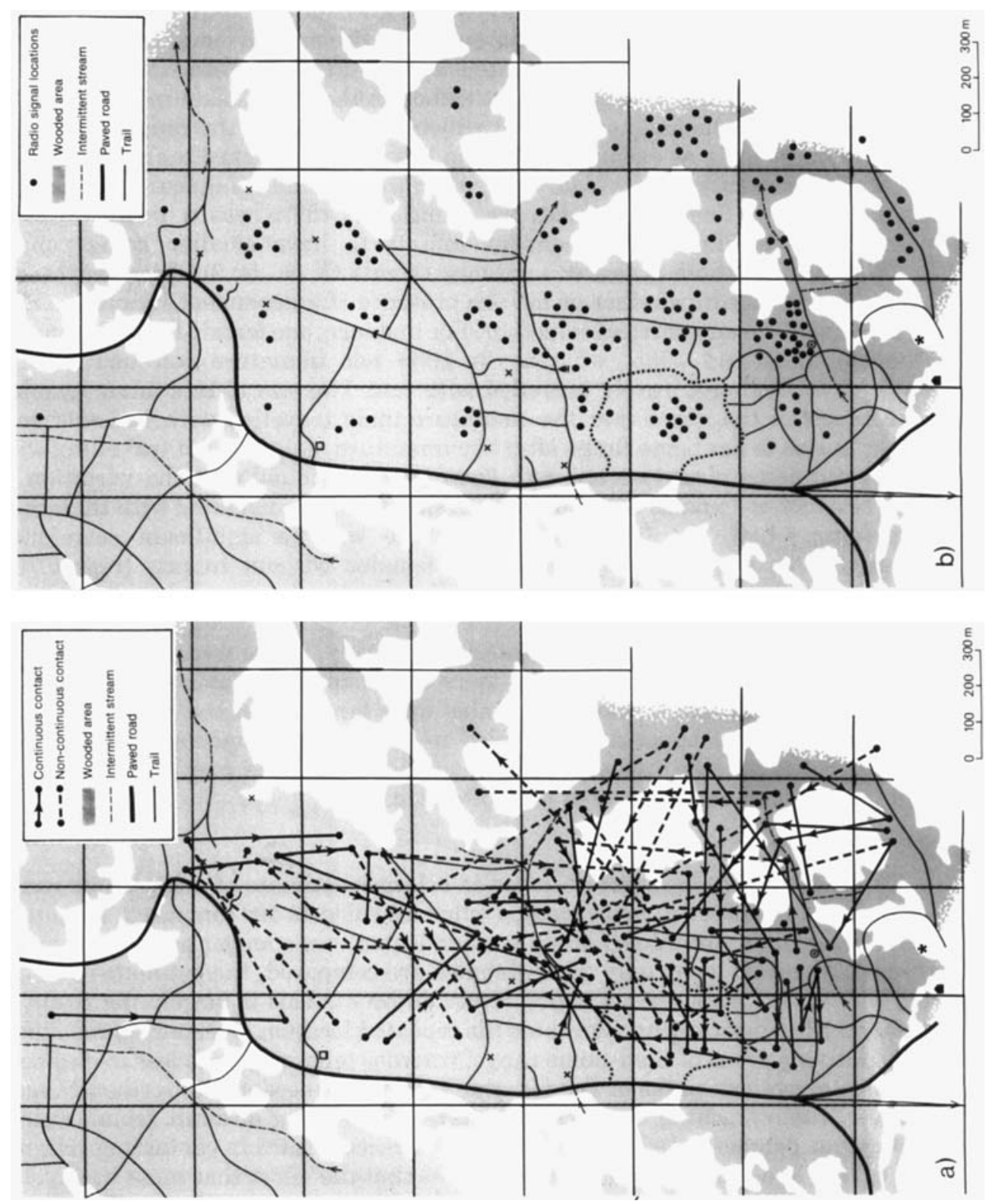
locating a particular individual. And whereas visual searches tend to be repeated in areas where the monkeys have been successfully located previously, tracking by radio signals rapidly leads the researcher into new areas of the range which might not otherwise be searched.

However there are a number of potential shortcomings to radio telemetry. Morris [1979] and MacDonald and Amlaner [1979] caution that published papers make radio tracking sound easier than it is, and that radio tracking is expensive, time consuming, and often frustrating. Thus, we would like to briefly discuss some of the difficulties we encountered in radio tracking the spider monkeys of Santa Rosa National Park. Potentially, the most constraining difficulty of radio telemetry is the possibility of technical failures. This constraint on the use of telemetry is particularly relevant when research is conducted in a remote area, which is often the case with primate field studies. With well-designed equipment, technical difficulties can be minimized, but nevertheless there is inevitable wear and tear on the receiver and the antenna. Thus it is essential to have backup equipment and someone in the field who can make minor repairs. A further difficulty is the capturing of the animals, which is necessary in order to attach the radios. The darting and chemical immobilization of aboreal primates, particularly fast-moving ones, is a skill that requires time and practice to develop. The wide-ranging males are particularly difficult to dart, since they are harder to find and more likely to retreat from a person attempting to dart them than are the females. Also, there is some risk of fatality resulting from the capture and, for some species, habituation may be disrupted. The final constraint to be mentioned here is the reduced efficiency of telemetry that we encountered during the rainy season. Santa Rosa is a tropical dry forest and experiences a 6-month dry season during which no appreciable rain falls, and the majority of the nonriparian trees lose their leaves. This expedited our radio-tracking project, but most field studies of forest-dwelling primates take place in wetter habitats with denser foliage.

In addition to illustrating the potential value and drawbacks of using radio telemetry to document the range use patterns of a fast moving arboreal primate, this study, along with McFarland's results [1986], provides support for the hypothesis that adult males have larger home ranges than adult females. We suggest that females occupy home ranges just large enough to adequately provide for their foraging needs. Adult males have larger home ranges than females, and we suggest that this represents an attempt by the male to increase the number of females he will contact.

Not only were sex differences in range size indicated by our results but there was also considerable variation in the home ranges of adult females. On average, females with infants occupy the smallest ranges, perhaps due to the energetic costs of carrying and lactating for their offspring. Although the sample size is admittedly small due to the difficulties in studying this species, we also found variation in range size within these categories. The lower-weight females with infants occupied the smallest home ranges, whereas weight was not found to correspond significantly to range size in females without infants. If the assumption that dominance provides priority of access to food resources is correct, then we might expect that in conditions of limited resources such as prevail in dry tropical forests, subordinate females would be in poorer condition than dominant females [see McFarland 1987, for findings and discussion of female-rank effects in Ateles]. If the

Fig. 2. Telemetric data and range maps for adult female number 4. a: Travel patterns. b: Locations from which subject number 4's radio signal emanated on one or more occasions. 


\section{8 / Fedigan et al.}

lower-weight females in our sample are also lower ranking ones, then our results indicate that subordinate females with infants are restricting (or are restricted in) their ranging patterns, whereas subordinate females without infants are not. We offer two possible reasons to account for this preliminary finding. One, subordinate females with infants may reduce their home ranges to decrease contacts with conspecifics and thus protect their infants from aggression. We have observed one attack and several wounds on dependent immature spider monkeys. Second, subordinate females with nursing infants are under double energetic constraints, reflecting both poorer access to food than dominant females, and greater maternal care costs than nonlactating females. Subordinate females may restrict travel to help counterbalance these two energetic disadvantages.

\section{CONCLUSIONS}

1. Radio telemetry is a feasible and efficient method of obtaining ranging data on an arboreal and fast-moving primate.

2. The radio-telemetry study produced significantly larger estimates of home range size than did the observational study when all subjects were compared. However, when only adult females were compared, the home range sizes determined by the two methods were not significantly different. The observational study required a much greater time investment.

3. The average home range of spider monkeys at Santa Rosa is 62.4 ha; however, home range size varies with sex, and for some females, with the presence of a dependent infant.

4. Male spider monkeys have larger home ranges than females. This difference lends support to the hypothesis that males spider monkeys have adapted to female dispersion by occupying a large home range that overlaps the ranges of several adult females.

5. There is a trend for females without infants to have larger home ranges than females with infants. For females with dependent infants, range size was related to weight, and thus possibly to dominance status.

\section{ACKNOWLEDGMENTS}

We wish to thank the National Parks Service of Costa Rica and the park guards for allowing us to conduct this research. We are grateful to M. Klassen, M. Jackson, K. Avery, G. Young, L. Munoz, K. Murie, R. Kaufman, M. MacDonald, L. Chapman, R. Morera, and W. Marshall for helping in capturing and radio tracking. This research was funded by an NSERC operating grant (A7723) to L.M. Fedigan and an NSERC post-graduate scholarship, a Province of Alberta Scholarship, and a University of Alberta Dissertation Fellowship to C. Chapman.

\section{REFERENCES}

Amlaner, C.J.; MacDonald, D.W. A HANDBOOK ON BIOTELEMETRY AND RADIO TRACKING. Pergamon Press, Oxford, 1979

Bearder, S.K.; Martin, R.D. The social organization of a noctural primate revealed by radio tracking. Pp. 633-648 in A HANDBOOK ON BIOTELEMETRY AND RADIO-TRACKING. C.J. Amlaner; D.W. MacDonald, eds. Oxford, Pergamon Press, 1979.

Cant, J. Ecology, locomotion and social orga- nization of spider monkeys (Ateles geoffroyi). Ph.D. dissertation, University of California, Davis, 1976.

Chapman, C.A. Foraging strategies, patch use, and constraints on group size in three species of Costa Rican primates. Ph.D. Dissertation, University of Alberta, Edmonton, 1987.

Chapman, C.A.; Chapman, L.J. Social responses to the traumatic injury of a juvenile spider monkey. PRIMATTES 28:1-10, 1987. 


\section{Spider Monkey Ranges / 29}

Charles-Dominique, P. Urine marking and territoriality in Galago alleni (Waterhouse, 1837-Lorisoidea, Primates),-a field study by radio telemetry. Z. TIERPSYCHOLOGY 43:113-138, 1977.

Charles-Dominique, P.; Bearder, S.K. Field studies of Lorisid behaviour: Methodological aspects. Pp. 567-629 in STUDY OF PROSIMIAN BEHAVIOUR. G.A. Doyle; R.D. Martin, eds. New York, Academic Press, 1979.

Coelho, A.M.; Coelho, L.S.; Bramblett, C.A.; Bramblett, S.S.; Quick, L.B. Ecology, population characteristics, and sympatric association in primates: A socio-bioenergetic analysis of howler and spider monkeys in Tikal, Guatemala. YEARBOOK OF PHYSICAL ANTHROPOLOGY, 20:95-135, 1976.

Fedigan, L.M.; Baxter, M.J. Sex differences and social organization in free-ranging spider monkeys (Ateles geoffroyi). PRIMATES 25:279-294, 1984

Gautier, J.P. Qualities and drawbacks of radiotransmitted vocalizations of monkeys through laryngophones: new perspectives in analysis. FOLIA PRIMATOLOGICA 41: 218-230, 1983.

Glander, K.E.; Fedigan, L.M.; Fedigan, L.; Chapman, C.A. Capture techniques for three species of monkeys in Costa Rica, In prep.

Harcourt, C.S.; Nash, L.T. Social organization of galagos in Kenyan costal forests: I Galago zanzibaricus. AMERICAN JOURNAL OF PRIMATOLOGY 10:339-355, 1986.

Janzen, D.H. GUANACASTE NATIONAL PARK: TROPICAL ECOLOGICAL, AND CULTURAL RESTORATION. Editorial Univ. Estatal a Distancia, San Jose, Costa Rica, 1986.

Jones, W.T.; Bush, B.B. Darting and marking techniques for an arboreal forest monkey, Cercopithecus ascanius. AMERICAN JOURNAL OF PRIMATOLOGY 14:8389, 1988.

Klein, L.L. The ecology and social organiza- tion of the spider monkey, Ateles geoffroyi. Ph.D. Dissertation, University of California, Berkeley, 1972.

Klein, L.L.; Klein, D.J. Social and ecological contrasts between four taxa of neotropical primates. Pp. 59-85 in SOCIOECOLOGY AND PSYCHOLOGY OF PRIMATES. R.H. Tuttle, ed. Hague, Moulton, 1975.

MacDonald, D.W.; Amlander, C.J. A practical guide to radio-tracking. Pp. 143-153 in A HANDBOOK ON BIOTELEMETRY AND RADIO-TRACKING. C.J. Amlaner; D.W. MacDonald, eds. Oxford, Pergamon Press, 1979.

McFarland, M. Ecological determinants of fission-fusion sociality in Ateles and Pan, pp. $181-190$ in PRIMATE ECOLOGY AND CONSERVATION. J.G. Else; P.C. Lee, eds. Cambridge, Cambridge University Press, 1986.

McFarland Symington, M. Sex ratio and maternal rank in wild spider monkeys: when daughters disperse. BEHAVIORAL ECOLOGY AND SOCIOBIOLOGY 20: 421-425, 1987.

Morris, P. An elementary guide to practical aspects of radio tracking mammals. Pp. 161-168 in A HANDBOOK ON BIOTELEMETRY AND RADIO TRACKING. C.J. Amlaner; D.W. MacDonald, eds. Oxford, Pergamon Press, 1979.

Nash, L.T.; Harcourt, C.S. Social organization of galagos in Kenyan costal forests: II Galago garnettii. AMERICAN JOURNAL OF PRIMATOLOGY 10:357-369, 1986.

Wrangham, R.W. On the evolution of ape social systems. SOCIAL SCIENCE INFORMATION 18:335-368, 1979a.

Wrangham, R.W. Sex differences in chimpanzee dispersion. Pp. 481-489 in THE GREAT APES, PERSPECTIVES ON HUMAN EVOLUTION, VOL. 5. D. Hamburg, E.R. McCown, eds. Menlo Park, Benjamin/Cummings, 1979b.

Wrangham, R.W. An ecological model of female-bonded primate groups. BEHAVIOR 75:262-300, 1980. 